Identification of saline soils with multi-year remote sensing of crop yields

\title{
UCRL-JRNL-225527
}

D. Lobell, I. Ortiz-Monasterio, F. Cajigas Gurrola, L. Valenzuela

October 24, 2006

Soil Science Society of America Journal 
This document was prepared as an account of work sponsored by an agency of the United States Government. Neither the United States Government nor the University of California nor any of their employees, makes any warranty, express or implied, or assumes any legal liability or responsibility for the accuracy, completeness, or usefulness of any information, apparatus, product, or process disclosed, or represents that its use would not infringe privately owned rights. Reference herein to any specific commercial product, process, or service by trade name, trademark, manufacturer, or otherwise, does not necessarily constitute or imply its endorsement, recommendation, or favoring by the United States Government or the University of California. The views and opinions of authors expressed herein do not necessarily state or reflect those of the United States Government or the University of California, and shall not be used for advertising or product endorsement purposes. 


\section{Identification of saline soils with multi-year remote sensing of crop yields}

\section{ABSTRACT}

Soil salinity is an important constraint to agricultural sustainability, but accurate

5 information on its variation across agricultural regions or its impact on regional crop

6 productivity remains sparse. We evaluated the relationships between remotely sensed

7 wheat yields and salinity in an irrigation district in the Colorado River Delta Region. The

8 goals of this study were to (1) document the relative importance of salinity as a constraint

9 to regional wheat production and (2) develop techniques to accurately identify saline

10 fields. Estimates of wheat yield from six years of Landsat data agreed well with ground-

11 based records on individual fields $\left(\mathrm{R}^{2}=0.65\right)$. Salinity measurements on 122 randomly

12 selected fields revealed that average 0-60 $\mathrm{cm}$ salinity levels $>4 \mathrm{dS} \mathrm{m}^{-1}$ reduced wheat

13 yields, but the relative scarcity of such fields resulted in less than $1 \%$ regional yield loss

14 attributable to salinity. Moreover, low yield was not a reliable indicator of high salinity,

15 because many other factors contributed to yield variability in individual years. However,

16 temporal analysis of yield images showed a significant fraction of fields exhibited

17 consistently low yields over the six year period. A subsequent survey of 60 additional

18 fields, half of which were consistently low yielding, revealed that this targeted subset had

19 significantly higher salinity at $30-60 \mathrm{~cm}$ depth than the control group $(\mathrm{p}=0.02)$. These

20 results suggest that high subsurface salinity is associated with consistently low yields in

21 this region, and that multi-year yield maps derived from remote sensing therefore provide

22 an opportunity to map salinity across agricultural regions. 
1 Abbreviations: ASTER, Advanced Spaceborne Thermal Emission and Reflection

2 Radiometer; ECa, apparent soil electrical conductivity; ECe, electrical conductivity of a

3 saturated soil extract; $\mathrm{EC}_{\mathrm{e}, 0-60}$, average ECe for 0-60 cm ; $\mathrm{EC}_{\mathrm{e}, 0-90}$, average $\mathrm{ECe}$ for 0-90

4 cm; ETM+, Enhanced Thematic Mapper Plus; fAPAR, the fraction of absorbed

5 photosynthetically active radiation; GLASOD, Global Assessment of Human-induced

6 Soil Degradation ; NDVI, normalized difference vegetation index; rmse, root mean

7 squared error; SAGARPA, Secretaría de Agricultura, Ganadería, Desarrollo Rural, Pesca

8 y Alimentación; TM, Thematic Mapper;

\section{INTRODUCTION}

11 Accumulation of salts in irrigated soils has represented an important threat to

12 agriculture throughout human history (e.g., Hillel, 1991). Presently, roughly $20 \%$ of

13 irrigated agriculture worldwide is thought to be negatively affected by salinization

14 (Ghassemi et al., 1995). However, large scale assessments such as GLASOD (Oldeman et

15 al., 1990) typically rely on expert judgments from individual countries or regions, and are

16 therefore "qualitative and (potentially) subjective" (description of GLASOD project

17 available at http://www.isric.nl/). As Lal et al. (2004) point out, "Despite its significance,

18 the available information on soil degradation is often based on reconnaissance surveys,

19 public opinion, extrapolations based on sketchy data, and casual observations by

20 interested travelers (p. 24).”

21 Improved inventories of the extent and impact of salinity in agricultural lands are

22 needed to more accurately assess the threat of salinization and to guide management

23 decisions and remediation efforts that can reduce productivity losses. The lack of 
1 objective, quantitative data reflects the difficulty of acquiring such information, in large

2 part because of the high degree of spatial and temporal heterogeneity of soil salinity.

3 Major advances have been made in the development and application of ground sensors

4 that can rapidly measure ECa (an excellent review is provided by Corwin and Lesch,

5 2003). ECa measurements are often highly correlated with variations in ECe, in particular

6 when soil moisture is near field capacity (Lesch and Corwin, 2003), thereby allowing one

7 to map soil ECe with non-invasive techniques. ECa sensors are thus invaluable tools for

8 mapping salinity within individual fields, but their ability to provide a comprehensive,

9 regional view of salinity's extent and impact remains limited because of the time and

10 expense required for each individual ECa survey.

11 Satellite-based remote sensing has been widely explored as an alternative to direct

12 field sampling because of its potential to cover large areas repeatedly through time.

13 However, these efforts have seen limited success due to a range of factors, as reviewed

14 by Metternicht and Zinck (2003). Approaches to detecting salinity with remote sensing

15 can be classified as either direct, in which the reflectance of bare soil itself is evaluated,

16 or indirect, in which vegetation type or condition is used as an indicator of salinity

17 (Metternicht and Zinck, 2003). Successful application of the direct approach using optical

18 remote sensing data requires low soil moisture, a high percentage of exposed bare soil,

19 and little variation in soil surface roughness due to factors other than salinity, such as

20 cultivation. In agricultural regions, all of these conditions are difficult to obtain because

21 of the predominance of crop and residue cover and the high spatial variability of

22 management practices. 
Alternatively, several studies have investigated the use of remotely sensed

2 indicators of canopy condition, such as the NDVI, to map soil salinity (Madrigal et al.,

3 2003; Wiegand et al., 1996; Wiegand et al., 1994). However, these approaches generally

4 assume that salinity is the only factor affecting crop condition, and therefore will only be

5 successful in situations where other factors are held constant (for instance by looking at

6 variations within an individual field with fixed management) or where salinity has an

7 extremely large impact on crop condition.

8 Given the shortcomings of traditional direct and indirect methodologies, we

9 sought to develop and test a new indirect approach that is useful under a broader range of

10 realistic agricultural settings. Rather than consider crop condition for any single date or

11 growing season, we utilized maps of crop yields for multiple years derived from satellite

12 data. Comparison of field measurements of salinity with remotely sensed yields was used

13 to evaluate the degree to which salinity is predictable from single year and multi-year

14 yield maps. The comparison of salinity with yields also provided insight into the overall

15 impact of salinity on regional production.

\section{METHODS}

\section{Site Description}

19 The San Luis Rio Colorado Valley (SLRCV) in Sonora, Mexico, is situated at the

20 mouth of the Colorado River just south of the United States border $\left(32.4^{\circ} \mathrm{N}, 114.8^{\circ} \mathrm{W}\right.$;

21 Figure 1). The Valley consists of roughly 27,000 irrigated Ha, sown predominantly to

22 wheat (Triticum aestivum) and a mix of vegetable crops. This study focused on the most

23 northern of three irrigation districts in SLRVC, which covers roughly 13,000 ha. The 
1 SLRCV lies within a region classified in GLASOD as having strong (not reclaimable)

2 degradation from salinization, but with infrequent extent ( $<5 \%$ of area; Oldeman et al.,

3 1990). In contrast, local researchers often identify salinization as one of the most

4 important constraints to crop production, with some reporting that up to $47 \%$ of land in

5 this region is affected by salinity (López 2001).

$6 \quad$ Wheat in SLRCV is typically planted in late fall (Nov-Dec) and harvested in

7 spring (Apr-May). Farmers normally apply one pre-plant and four auxiliary irrigations in

8 a traditional basin irrigation system where wheat is planted as a flat, solid stand. The

9 irrigation water for the entire SLRCV district is derived from a roughly equal fraction of

10 surface and groundwater sources, although this fraction varies considerably throughout

11 the region (López, 2001). Typical fertilizer rates are $250 \mathrm{~kg} \mathrm{~N}$ and $50 \mathrm{~kg} \mathrm{P} \mathrm{ha}^{-1}$, and

12 yields average $6.0-7.5$ ton ha ${ }^{-1}$, depending on year. Soils in this region are classified as

13 Vertic Haplocalcids.

\section{Remote Sensing Analysis}

16 A combination of ASTER, Landsat TM, and ETM+ images was acquired for each

17 of the six growing seasons of wheat from $2000-2005$ (Table 1). These images were first

18 converted to top of atmosphere reflectance using standard sensor calibration values (Irish,

19 1999) and georeferenced to within $30 \mathrm{~m}$. The ratio of near-infrared to red reflectance (i.e.,

20 Landsat band 4 / band 3), which is positively correlated with vegetation abundance

21 (Tucker, 1979), exhibited a bimodal distribution for most images. A simple threshold

22 applied to each image therefore provided an indicator of pixels with active crops (Lobell

23 et al., 2003). Pixels that contained active crops in all images acquired during the wheat 
1 growing season were identified as wheat. To validate this approach, the area of pixels

2 identified as wheat was summed over the irrigation district and compared with official

3 area reports from SAGARPA (Secretaría de Agricultura, 2005), revealing errors below

$42 \%$ in all but one year and an rmse of just 2.4\% (Table 2).

5 Yields were estimated for each wheat pixel using the technique of (Lobell et al.,

6 2003), which is based on a simple light-use efficiency model. Briefly, fAPAR is

7 estimated from reflectance values in each Landsat image using previously established

8 relationships (e.g., Los et al., 2000). Values of fAPAR are then interpolated for each day

9 during the growing season using a pre-defined, temperature-based phenology model, and

10 the daily fAPAR values are multiplied by incident radiation measured at a local

11 meteorological station to estimate total light absorption throughout the growing season.

12 Values for light-use efficiency and harvest index (the ratio of grain to aboveground

13 biomass), based on field data, are then used to translate light absorption into estimates of

14 wheat yields. This approach has been successfully applied in the Yaqui Valley, another

15 wheat region in Sonora, Mexico (Lobell et al., 2003; Lobell et al., 2005).

16 Despite the previous validation in a region with similar characteristics, we sought

17 to independently evaluate the wheat yield estimates in SLRCV. Ground-based

18 measurements of field-averaged yields across a commercial landscape inevitably requires

19 the reliance on farmer records of grain harvests. This is especially true when attempting

20 to validate yield estimates for prior years. As a result, substantial errors in "ground-truth"

21 yields may exist because of inaccuracies in farmer reports. We obtained records from

22 local credit unions that contained farmer reported yields for three years: 2000, 2002, and

23 2005. Any yields below 3 ton ha ${ }^{-1}$ or above 9 ton ha ${ }^{-1}$ were deemed unreliable and were 
1 omitted from comparison with remote sensing estimates. In addition, the locations of

2 some fields were ambiguously identified, and these were therefore also omitted. A total

3 of 43 farmer-reported yield values remained for validation.

4

5

6

7

8 selected fields in the irrigation district. The main goal of this survey was to document the

9 distribution of salinity values within SLRCV and compare salinity levels to remotely

10 sensed yields. Soil cores were taken at random locations within each of four quadrants of

11 each field, and then combined to produce a single field sample for $0-30 \mathrm{~cm}$ and $30-60 \mathrm{~cm}$.

12 The stratified random sample (with $n=4$ ) was based on measurements of within field

13 heterogeneity of salinity for ten fields (Lobell, unpublished data), which indicated that

14 this approach would result in estimates of ECe with rmse $<0.5 \mathrm{dS} \mathrm{m}^{-1}$.

15 A second, targeted field campaign was conducted in September 2005 and May-

16 June 2006. Based on the observed relationships between ECe and wheat yields (see

17 below), we hypothesized that fields with consistently low yields were more likely to

18 contain high ECe. To test this hypothesis, a stratified random sample was collected. All

19 pixels were first classified into two groups: (1) those that had wheat in at least five of the

20 six years and whose yields were always below the $80^{\text {th }}$ percentile of yields, and (2) all

21 other pixels. Thirty fields were randomly selected from each group, forming a "target"

22 and “control” sample. Due to logistical constraints, twenty fields (ten from each group)

23 were visited prior to planting of the 2005-2006 wheat crop (in September) and another 
1 forty fields were sampled after harvest (May-June). Samples were collected for three

2 depths: $0-30 \mathrm{~cm}, 30-60 \mathrm{~cm}$, and $60-90 \mathrm{~cm}$.

3

4

5

6

7

8 line (Figure 2). As discussed above, the farmer-reported values represent an independent

9 estimate of yields but are not without error. Unfortunately, a reliable estimate of the rmse

10 between farmer-reported values and actual yields is not available, as it would require an

11 extensive effort to measure harvests in each field. The agreement with the remotely

12 sensed estimates nonetheless gives confidence that remote sensing measurements provide

13 a reliable indicator of wheat productivity in this region.

17 Of the 122 surveyed fields, 10 had average $0-60 \mathrm{~cm}$ values above $3 \mathrm{dS} \mathrm{m} \mathrm{m}^{-1}$, and only two

18 were above $4 \mathrm{dS} \mathrm{m} \mathrm{m}^{-1}$. Salinity values generally increased with depth (Table 3), suggesting

19 that average salinity in the entire root zone, which extends to roughly $1 \mathrm{~m}$, was likely

20 higher than averages for the top $60 \mathrm{~cm}$. Indeed, measurements from the second survey,

21 when depths of $60-90 \mathrm{~cm}$ were sampled, showed that ECe for $0-60 \mathrm{~cm}$ and $0-90 \mathrm{~cm}$ were

22 highly correlated and could be related by the equation:

$$
\mathrm{EC}_{\mathrm{e}, 0-90}=1.05 * \mathrm{EC}_{\mathrm{e}, 0-60}-0.08, \quad \mathrm{R}^{2}=0.96
$$


3 Thus, values of 3.0 and $4.0 \mathrm{dS} \mathrm{m}^{-1}$ for 0-60 cm salinity correspond roughly to 3.1 and 4.1

$4 \mathrm{dS} \mathrm{m} \mathrm{m}^{-1}$, respectively, for 0-90 $\mathrm{cm}$.

5 Using the standard threshold of $4 \mathrm{dS} \mathrm{m}^{-1}$ for defining a field as saline (Hillel,

6 1998), only one out of 122 fields was technically saline for 0-30 cm, although nine

7 exceeded this threshold for 30-60 cm. Moreover, wheat is classified by the USDA

8 Salinity Laboratory as a salt tolerant crop and is commonly believed to show negligible

9 yield response up to $6 \mathrm{dS} \mathrm{m} \mathrm{m}^{-1}$ (Maas and Hoffman, 1977), a value exceeded by only one

10 field for $30-60 \mathrm{~cm}$ and none for $0-30 \mathrm{~cm}$. The field salinity measurements, combined with

11 standard criteria for salinity classifications, thus suggest that salt-related yield losses in

12 this region are currently rare.

13

\section{Salinity-Yield Relationships}

15 As soil samples were acquired during the 2005 season, we first compared soil

16 ECe with yields from this season alone (Figure 4a). (Because fields were selected

17 randomly without regard to crop type, only 72 of the 122 sampled fields had wheat in

18 2005.) Salinity at 0-30cm and 30-60 cm both were weakly related to yields, although all

19 fields near or above $4 \mathrm{dS} \mathrm{m}^{-1}$ in average $0-60 \mathrm{~cm}$ salinity exhibited relatively low yields.

20 Interestingly, average yields exhibited a slight decline with increased salinity even at

21 fairly low ECe (Figure 4). This suggests that the threshold model of salinity response

22 may be an over-simplification (Katerji et al., 2003), and/or that fields with an average

23 ECe of, e.g., $2 \mathrm{dS} \mathrm{m} \mathrm{m}^{-1}$ are more likely to have parts of the field above critical salinity 
1 levels than fields with lower average ECe. In either case, the effect of salinity appears

2 only minor until average ECe exceeding $4 \mathrm{dS} \mathrm{m}^{-1}$. This, combined with the fact that few

3 fields exceeded ECe of $4 \mathrm{dS} \mathrm{m}^{-1}$, confirms the notion that salinity has an overall small

4 impact on regional wheat productivity. For example, the average yield estimate for fields

5 with ECe $<1 \mathrm{dS} \mathrm{m}^{-1}$ was 6.77 ton ha $^{-1}$, while the average for all surveyed fields was 6.72

6 ton $\mathrm{ha}^{-1}$. If one assumes that salinity is uncorrelated with other factors that affect yields,

7 than the regional yield loss due to salinity in this region was just $0.8 \%$ in 2005 .

8 Figure 4 also clearly illustrates that low yields were not a reliable indicator of

9 high salinity, since many low yielding fields had low values of $\mathrm{EC}_{\mathrm{e}}$. This is consistent

10 with the notion that salinity is just one of many factors that can reduce yields. In this

11 region, it appears that factors unrelated to ECe are the predominant cause of low yields in

12 any single year. However, if these other factors were associated with management

13 practices or weather conditions that varied from year to year, and salinity levels are

14 assumed to be fairly stable over a five year period, then one would expect multi-year

15 yield statistics to provide more reliable indicators of soil salinity.

16 Unfortunately, the low number of fields exceeding $4 \mathrm{dS} \mathrm{m}^{-1}$ in the January survey

17 prohibited a reliable estimate of multi-year statistics for high salinity fields. As an

18 alternative way to test the hypothesis that saline fields result in consistently low yields,

19 we computed the proportion of fields that exhibited consistently low yields and compared

20 it with the proportion expected by chance. If the former is significantly larger than the

21 latter, then the presence of a factor that consistently suppresses yields is indicated.

22 For example, Figure 5 shows the proportion of image pixels (out of those that had

23 wheat in all six years) that were above a specified yield threshold for $0,1,2,3,4,5$, and 6 
1 years. Since the average yield varied between years, yield images for each year were

2 converted to percentiles instead of yields, with $0 \%$ and $100 \%$ corresponding to the

3 minimum and maximum estimated yield throughout the Valley for each year. The null

4 distribution (i.e. the number of pixels, $\mathrm{x}$, expected by chance) was calculated based on the

5 binomial distribution:

$$
\mathrm{p}(\mathrm{X}=\mathrm{x})={ }_{\mathrm{n}} \mathrm{C}_{\mathrm{x}}(1-\mathrm{p})^{\mathrm{x}} \mathrm{p}^{(\mathrm{n}-\mathrm{x})}
$$

7 where $\mathrm{p}$ is the threshold used. Figure 5 shows the observed and null distribution for $\mathrm{p}=$

$850 \%$ and $\mathrm{p}=80 \%$. In both cases, significantly more pixels were observed to exceed the

9 threshold in 0 years than expected by chance, indicating the presence of a consistent,

10 yield-suppressing factor. For example, roughly $39 \%$ of pixels never exceeded $80 \%$,

11 whereas only $26 \%$ of such pixels were expected by chance. While it is, of course,

12 possible that factors other than salinity, such as poor management, contribute to

13 consistently low yields, the high proportion of consistently low yielding fields suggests

14 that this multi-year statistic provides useful information on some yield controlling

15 factor(s), which may or may not include salinity.

\section{Targeted Field Sample}

18 To further test the hypothesis that multi-year yield statistics can be used to

19 identify saline fields, measured ECe for the "target" and "control" groups in the second

20 survey were compared (Table 4, Figure 6). The distribution of ECe within each group

21 were generally not Gaussian (Figure 6), and therefore the non-parametric Mann-Whitney

22 test was used to test differences in salinity distributions between groups. Average ECe in

23 the targeted group were higher than the control at all depths, consistent with the 
1 hypothesis that consistently low yields indicate the presence of elevated salinity levels.

2 These differences were not statistically significant at $0-30 \mathrm{~cm}$ depth $(\mathrm{p}=0.27)$, but were

3 highly significant at 30-60 $\mathrm{cm}(\mathrm{p}=0.02)$ and moderately significant for 0-60 $\mathrm{cm}$ and 30-

$490 \mathrm{~cm}$ average salinities $(\mathrm{p}<0.10)$. Significance at $60-90 \mathrm{~cm}(\mathrm{p}=0.13)$ was lower than

5 for 30-60 cm but higher than for 0-30 cm.

6 Two reasons likely explain the unique importance of salinity at $30-60 \mathrm{~cm}$ for

7 wheat yields in this region. First, salinity values at 0-30 cm depth were generally lower

8 than at 30-60 $\mathrm{cm}$ and almost always below $4 \mathrm{dS} \mathrm{m}^{-1}$ (Figure 6). Values at 30-60 $\mathrm{cm}$, in

9 contrast, were more frequently above $4 \mathrm{dS} \mathrm{m}^{-1}$, and thus more likely to exert an influence

10 on crop growth. Values at $60-90 \mathrm{~cm}$ also commonly exceeded this threshold; however the

11 fraction of wheat roots reaching below $60 \mathrm{~cm}$ is typically much smaller than the fraction

12 found at 30-60 cm (Manske and Vlek, 2002). Thus, 30-60 cm represents an overlap

13 between depths of relatively high salinity (below $30 \mathrm{~cm}$ ) and depths of significant

14 amounts of wheat roots (above $60 \mathrm{~cm}$ ).

15 The importance of 30-60 cm salinity illustrates that measures of surface salinity,

16 such as those made with the direct remote sensing techniques discussed in the

17 Introduction, may be of limited relevance to crop production even if they are perfectly

18 accurate. Indirect methods that rely on measures of crop stress, such as the approach

19 presented here, may therefore provide more reliable indicators of crop-relevant salinity.

20 This conclusion, though, may depend on region-specific cropping patterns, salinity levels,

21 and correlations between $0-30 \mathrm{~cm}$ and $30-60 \mathrm{~cm}$ salinity values, 
Given the difficulty of assessing soil salinity and its impact on productivity at the

2 regional scale using traditional approaches, we evaluated the potential contribution of

3 yield datasets derived from remote sensing. Remote sensing allows a fairly rapid and

4 accurate assessment of wheat yields at hundreds of individual fields through time, a

5 dataset that would be very difficult to obtain by other means. Comparison of yields with

6 salinity measurements acquired randomly throughout the region revealed a very small

7 impact of salinity on regional wheat production. The low frequency of $\mathrm{EC}_{\mathrm{a}}$ values

8 exceeding $4 \mathrm{dS} \mathrm{m}^{-1}$, the relative tolerance of wheat to salinity, and the presence of other

9 factors that reduce yields combine to explain the insubstantial effect of salinity on

10 production in this region. It is possible that remotely sensed yield or biomass estimates

11 for other crops, such as alfalfa or vegetables, which are more sensitive to salinity would

12 present greater correlations with salinity. However, the area surveyed using these crops

13 would be significantly smaller.

14 A previous study (Madrigal et al., 2003) reported much stronger relationships

15 between wheat yields and salinity in a nearby region in Northwest Mexico than found

16 here. The authors then used this correlation along with NDVI images to calculate that

$1758 \%$ of soils were salt-effected. However, their training sample was not obtained

18 randomly, but rather by selecting areas with visible salinity problems. This led, for

19 instance, to the inclusion of $\mathrm{EC}_{\mathrm{a}}$ values as high as $20 \mathrm{dS} \mathrm{m}{ }^{-1}$ in the training set. While this

20 approach may be useful for investigating yield responses to high levels of salinity, their

21 implicit assumption that the training set was representative of the entire region was

22 unjustified. As shown in the current study, many factors other than salinity contribute to 
1 yield losses throughout an entire agricultural region, and yields in a single year therefore

2 do not generally provide a reliable predictor of soil salinity.

3 Based on the hypothesis that yield-reducing factors other than soils will tend to

4 vary between years, we evaluated the use of multi-year yield images to identify problem

5 areas. Samples acquired on consistently low yielding fields exhibited significantly higher

6 salinity levels at 30-60 cm depth, indicating that sub-soil salinity affects wheat yields in

7 this region. The use of multi-year statistics therefore appears promising for identifying

8 saline hotspots, although additional work is needed to test this approach, particularly in

9 regions where salinity is a more common problem in crop productivity. Any increase in

10 the efficiency and accuracy of salinity surveys would be a welcome advance, given the

11 tremendous expense and difficult of regional salinity mapping with solely ground-based

12 methodologies.

13

\section{REFERENCES}

15 Corwin, D.L., and S.M. Lesch. 2003. Application of soil electrical conductivity to

16 precision agriculture: Theory, principles, and guidelines. Agron. J. 95:455-471.

17 Ghassemi, F., A.J. Jakeman, and H.A. Nix. 1995. Salinisation of land and water

18 resources: human causes, extent, management and case studies CAB

19 International, Canberra, Australia.

20 Hillel, D. 1991. Out of the earth: civilization and the life of the soil Macmillan, New

$21 \quad$ York.

22 Hillel, D. 1998. Environmental Soil Physics Academic Press, San Diego, CA. 
1 Irish, R. 1999. Landsat 7 Science Data Users Handbook [Online]. Available by Landsat Project Science Office, Goddard Space Flight Center http://tpwww.gsfc.nasa.gov/IAS/handbook.html.

4 Katerji, N., J.W. van Hoorn, A. Hamdy, and M. Mastrorilli. 2003. Salinity effect on crop development and yield, analysis of salt tolerance according to several classification methods. Agric. Water Manag. 62:37-66.

7 Lal, R., T.M. Sobecki, T. Iivari, and J.M. Kimble. 2004. Soil Degradation in the United States: extent, severity, and trends CRC Press, Boca Raton, FL.

9 Lesch, S.M., and D.L. Corwin. 2003. Using the dual-pathway parallel conductance model to determine how different soil properties influence conductivity survey data. Agron. J. 95:365-379.

12 Lobell, D.B., G.P. Asner, J.I. Ortiz-Monasterio, and T.L. Benning. 2003. Remote sensing 13 of regional crop production in the Yaqui Valley, Mexico: estimates and uncertainties. Agriculture, Ecosystems, and Environment 94:205-220.

15 Lobell, D.B., J.I. Ortiz-Monasterio, G.P. Asner, R.L. Naylor, and W.P. Falcon. 2005.

16 Combining field surveys, remote sensing, and regression trees to understand yield variations in an irrigated wheat landscape. Agron. J. 97:241-249.

18 López, L.A. 2001. Water salinity in Irrigation District 014, Río Colorado, B.C. y Sonora (in Spanish). First International Conference on Salinity of the Colorado River.

20 Los, S.O., G.J. Collatz, P.J. Sellers, C.M. Malmstrom, N.H. Pollack, R.S. Defries, L.

21 Bounoua, M.T. Parris, C.J. Tucker, and D.A. Dazlich. 2000. A global 9-yr

22 biophysical land surface dataset from NOAA AVHRR data. Journal of

$23 \quad$ Hydrometeorology 1:183-199. 
1 Maas, E.V., and G.J. Hoffman. 1977. Crop salt tolerance, current assessment. Journal of

2 the Irrigation and Drainage Division ASCE 103:115-134.

3 Madrigal, L.P., C.L. Wiegand, J.G. Meraz, B.D.R. Rubio, X.C. Estrada, and O.L.

4 Ramirez. 2003. Soil salinity and its effect on crop yield - a study using satellite

5 imagery in three irrigation districts. Ingenieria Hidraulica En Mexico 18:83-97.

6 Manske, G.B., and P.L.G. Vlek. 2002. Root architecture-wheat as a model plant, p. 249-

7 259, In Y. Waisel, et al., eds. Plant Roots: The Hidden Half. Marcel Dekker, Inc.,

$8 \quad$ New York.

9 Metternicht, G.I., and J.A. Zinck. 2003. Remote sensing of soil salinity: potentials and

10 constraints. Remote Sens. Environ. 85:1-20.

11 Oldeman, L.R., R.T.A. Hakkeling, and W.G. Sombroek. 1990. World map of the status

12 of human-induced soil degradation: an explanatory note. International Soil

13 Reference and Information Centre, Nairobi.

14 Secretaría de Agricultura, G., Desarrollo Rural, Pesca y Alimentación (SAGARPA).

15 2005. Sistema Integral de Informacion Agroalimentaria y Pesquera [Online]

$16 \quad$ http://www.siap.sagarpa.gob.mx/.

17 Tucker, C.J. 1979. Red and Photographic Infrared Linear Combinations for Monitoring

18 Vegetation. Remote Sens. Environ. 8:127-150.

19 Wiegand, C., G. Anderson, S. Lingle, and D. Escobar. 1996. Soil salinity effects on crop

20 growth and yield - Illustration of an analysis and mapping methodology for

$21 \quad$ sugarcane. J Plant Physiol 148:418-424. 
1 Wiegand, C.L., J.D. Rhoades, D.E. Escobar, and J.H. Everitt. 1994. Photographic and Videographic Observations For Determining and Mapping the Response of Cotton to Soil-Salinity. Remote Sens. Environ. 49:212-223.

4

This work was performed under the auspices of the U. S. Department of Energy by University of California, Lawrence Livermore National Laboratory under contract W-7405-Eng-48. 
2 1) The San Luis Rio Colorado Valley study region, as seen in band 3 of a Landsat TM+

3 image from Mar 31, 2002. Pixels with wheat appear dark in this image. Locations of field

4 samples in surveys are also shown.

62 2) Comparison of image-based yield estimates with farmer reported yields for 43 fields.

8 3) Histograms of field average soil electrical conductivity ( $\mathrm{dS} \mathrm{m}^{-1}$ ) at depths of 0-30 $\mathrm{cm}$ 9 and $30-60 \mathrm{~cm}$.

11 4) Comparison of soil electrical conductivity ( $\mathrm{dS} \mathrm{m}^{-1}$ ) measured in January 2005 at (a) 0-

$1230 \mathrm{~cm}$ (b) 30-60 cm and (c) 0-60 cm with image-based yield estimates for 2005.

14 5) Histograms of the number of years a pixel exceeded the $50^{\text {th }}$ (a) and $80^{\text {th }}$ (b) percentiles 15 of yield in SLRCV (black lines). Only pixels with yields in all six years were included in

16 histogram. Dashed gray lines shows null distribution expected for random yield

17 variations. Significantly more fields than expected by chance were never above the given

18 yield percentiles, suggesting the existence of factors that consistently suppress yields.

20 6) Histograms of field average soil electrical conductivity $\left(\mathrm{dS} \mathrm{m}{ }^{-1}\right)$ at depths of $0-30 \mathrm{~cm}$,

21 30-60 cm, and 60-90 cm for 30 randomly chosen fields (left) and 30 "targeted" fields

22 (right), which had remotely sensed yields always below the $80^{\text {th }}$ percentile. 
1 Table 1. Images used for wheat area and yield estimation in each harvest year.

\begin{tabular}{|c|c|c|c|}
\hline Harvest Year & TM Images & ETM+ Images & ASTER Images \\
\hline 2000 & & Feb 22, Apr 10 & \\
\hline 2001 & & Jan 23, Mar 28 & \\
\hline 2002 & & Feb 11, Mar 31 & \\
\hline 2003 & & Jan 29 & Apr 4 \\
\hline 2004 & Feb 9, Mar 28 & & \\
\hline 2005 & Feb 27, Mar 31 & & \\
\hline
\end{tabular}

2

3 
1 Table 2. Comparison of wheat area estimates from remote sensing with reported wheat 2 area from SAGARPA.

\begin{tabular}{ccccccc} 
& 2000 & 2001 & 2002 & 2003 & 2004 & 2005 \\
\hline Reported Area (Ha) & 16,250 & 17,000 & 16,224 & 16,809 & 16,159 & 14,155 \\
Estimated Area (Ha) & 16,549 & 17,063 & 16,073 & 15,895 & 16,288 & 14,306 \\
\% Difference & 1.8 & 0.4 & -0.9 & -5.4 & 0.8 & 1.1 \\
\hline
\end{tabular}

3

4 
1 Table 3. Summary statistics for ECe $\left(\mathrm{dS} \mathrm{m}^{-1}\right)$ and $\mathrm{pH}$ in January soil samples $(\mathrm{n}=122)$.

\begin{tabular}{cccccccc} 
& mean & $\begin{array}{c}\text { Standard } \\
\text { deviation }\end{array}$ & 0 & 25 & 50 & 75 & 100 \\
\hline ECe, 0-30 cm & 1.42 & 0.72 & 0.40 & 0.97 & 1.26 & 1.71 & 4.58 \\
ECe, 30-60 cm & 1.90 & 1.18 & 0.37 & 1.17 & 1.61 & 2.17 & 8.86 \\
ECe, 0-60 cm & 1.66 & 0.91 & 0.46 & 1.11 & 1.44 & 1.95 & 6.72 \\
pH, 0-60 cm & 7.63 & 0.22 & 7.05 & 7.49 & 7.61 & 7.78 & 8.19 \\
\hline
\end{tabular}

2

3 
1 Table 4. Summary statistics for ECe (dS m$\left.{ }^{-1}\right)$ in target and control groups in 2005-2006

2 soil survey. Each group contained 30 fields, whose histograms are shown in Figure 6.

\begin{tabular}{cccc}
\hline Depth $(\mathrm{cm})$ & Control mean & Target Mean & $\begin{array}{c}\text { Mann-Whitney p- } \\
\text { value }\end{array}$ \\
\hline $0-30$ & 2.0 & 2.2 & .27 \\
$30-60$ & 2.1 & 2.8 & .02 \\
$60-90$ & 2.2 & 3.0 & .13 \\
$0-90$ & 2.1 & 2.5 & .13 \\
$0-60$ & 2.0 & 2.5 & .09 \\
$30-90$ & 2.2 & 2.9 & .08 \\
\hline
\end{tabular}

3

4

5 


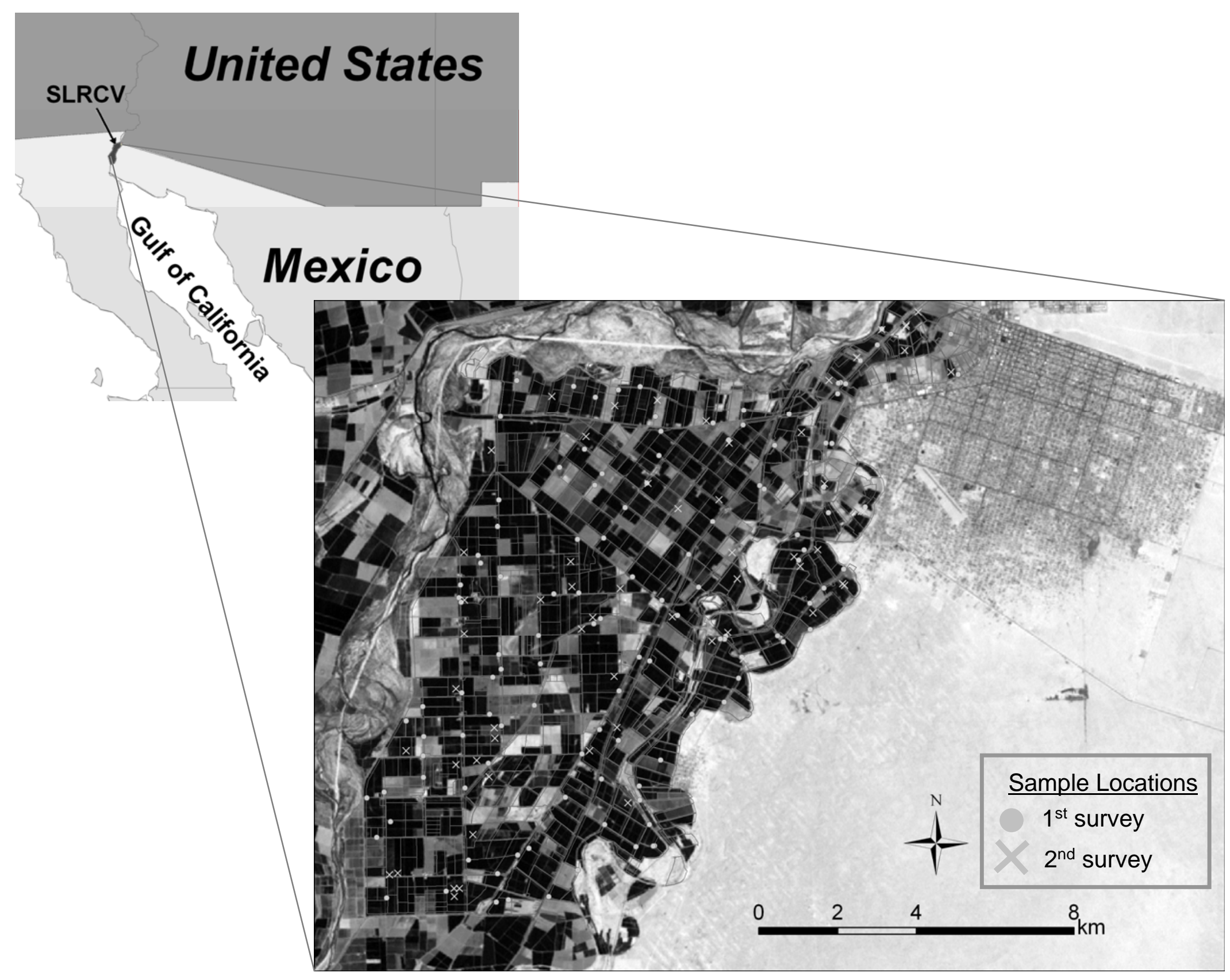




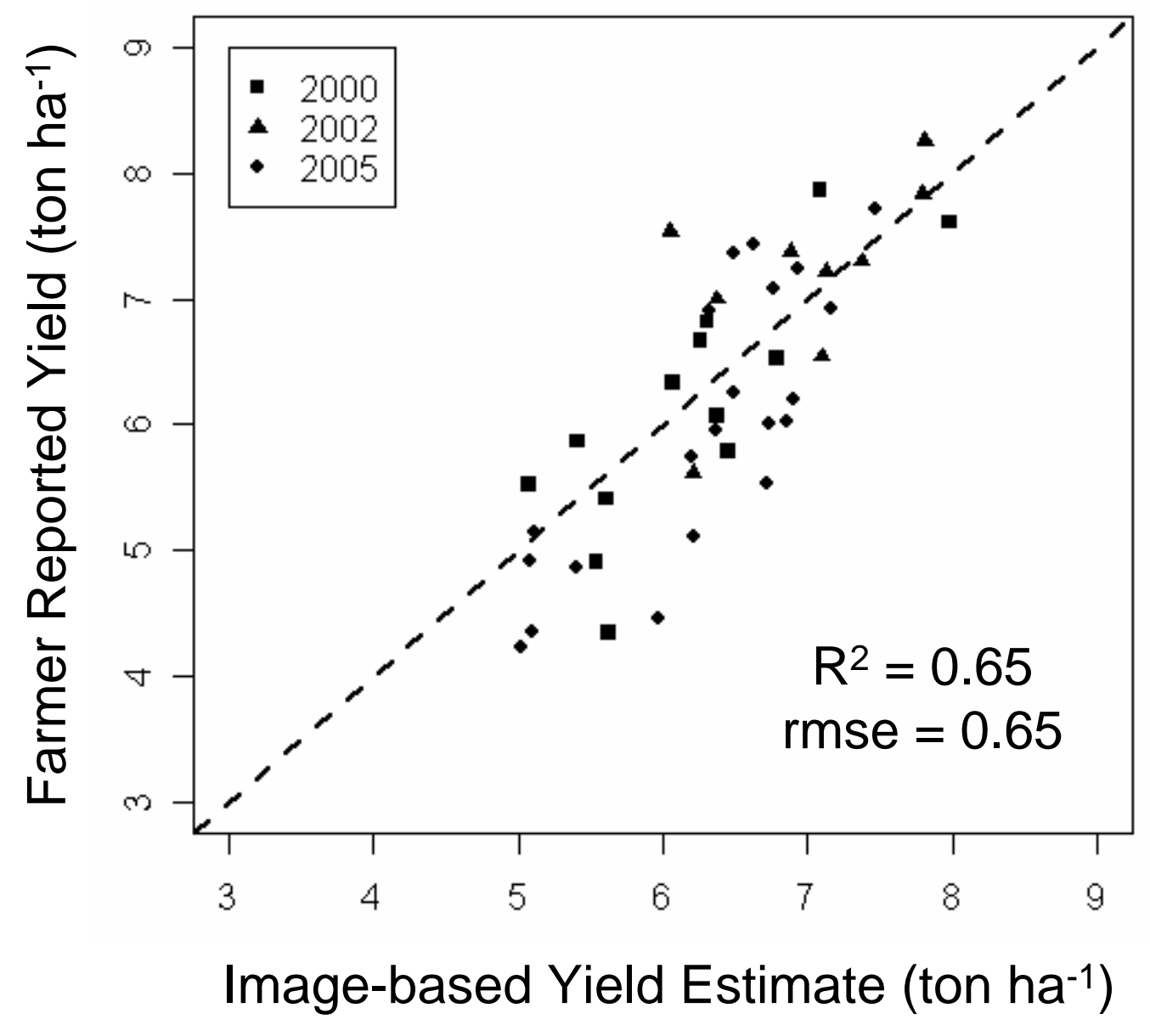



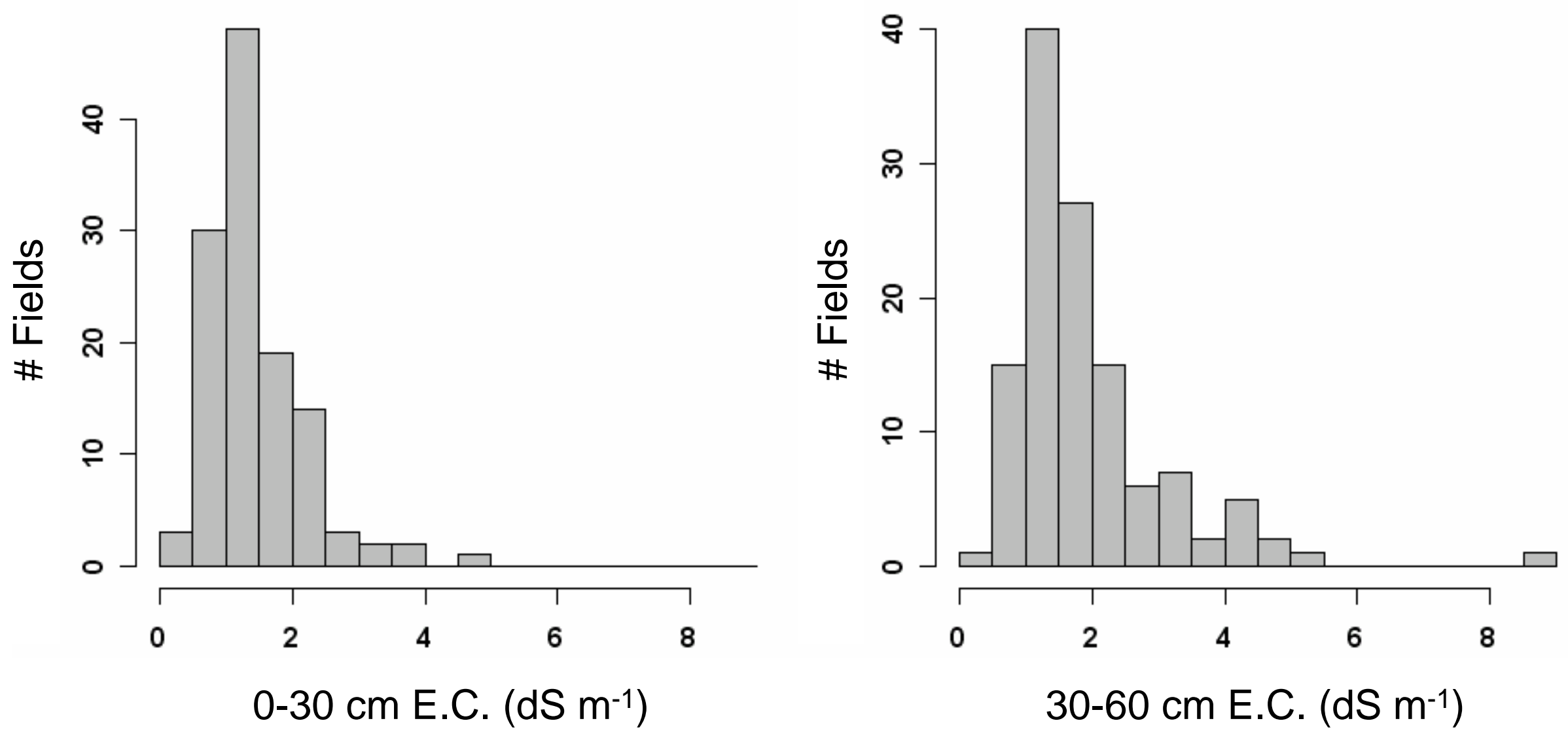

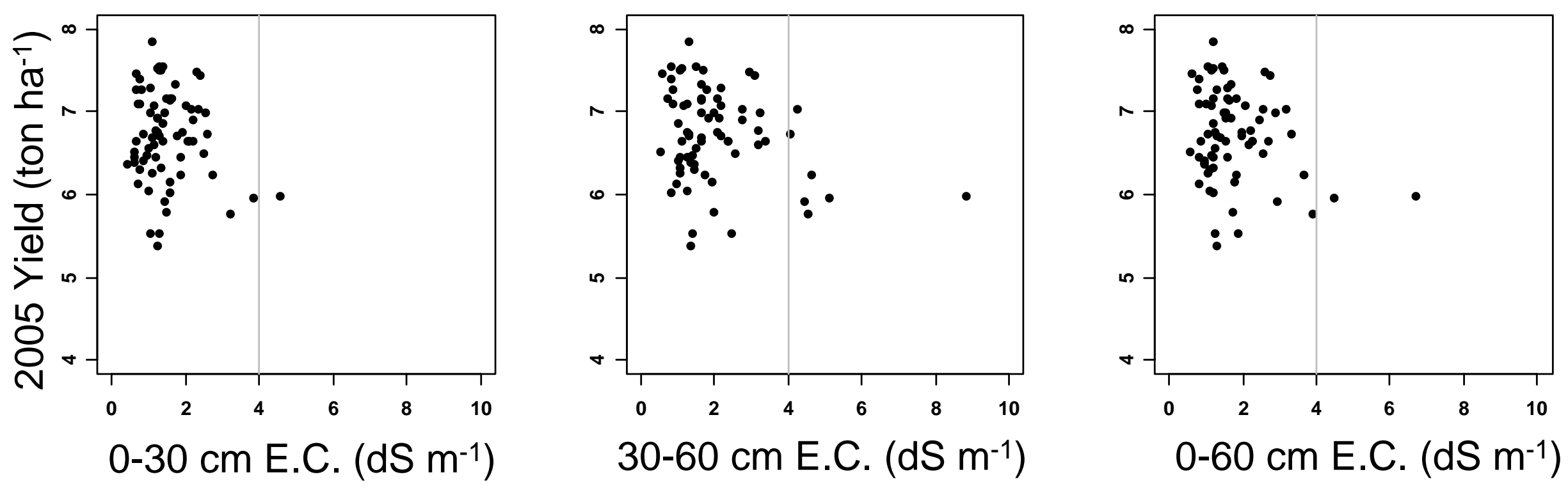


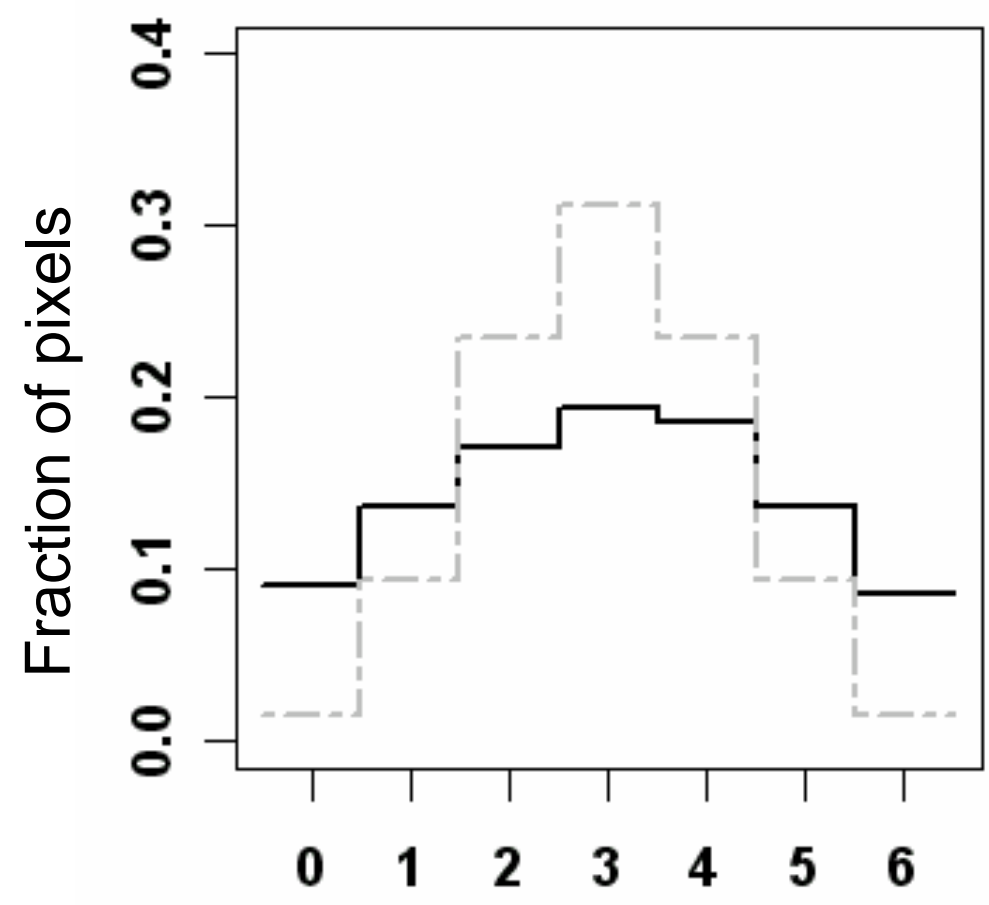

\# Years Above $50^{\text {th }}$ percentile

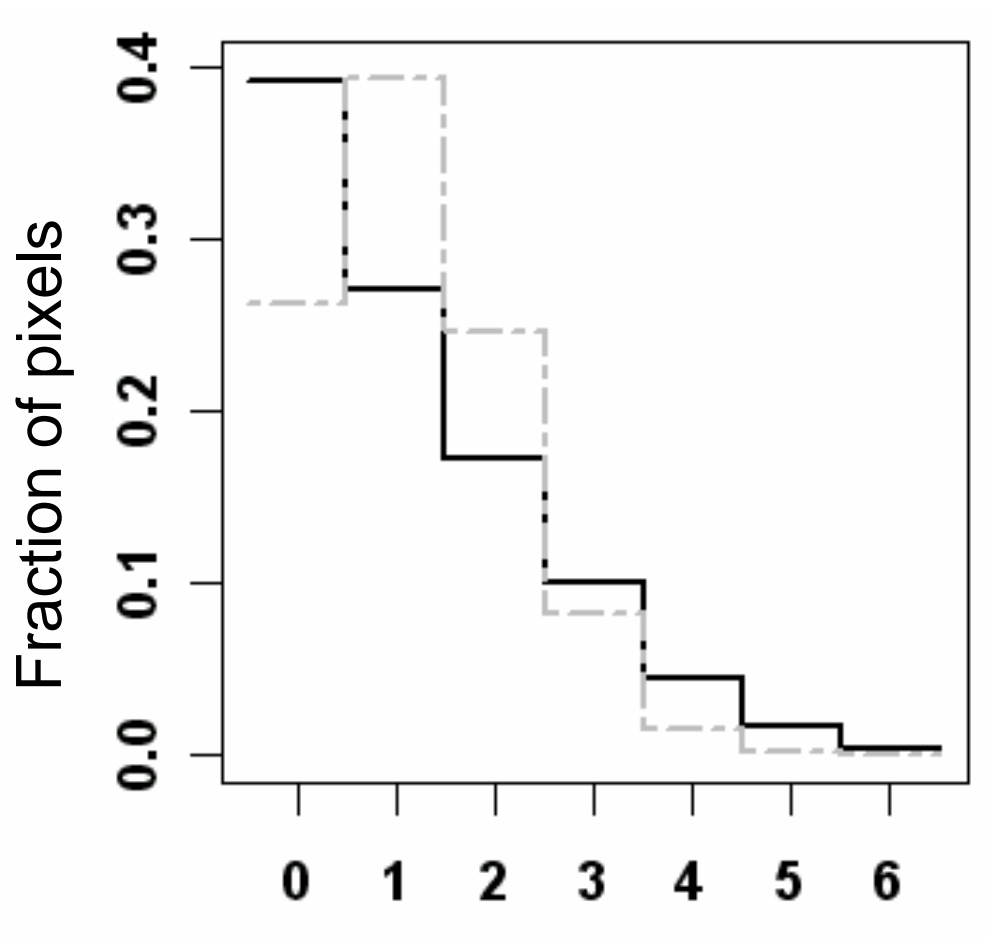

\# Years Above $80^{\text {th }}$ percentile 
Control Group
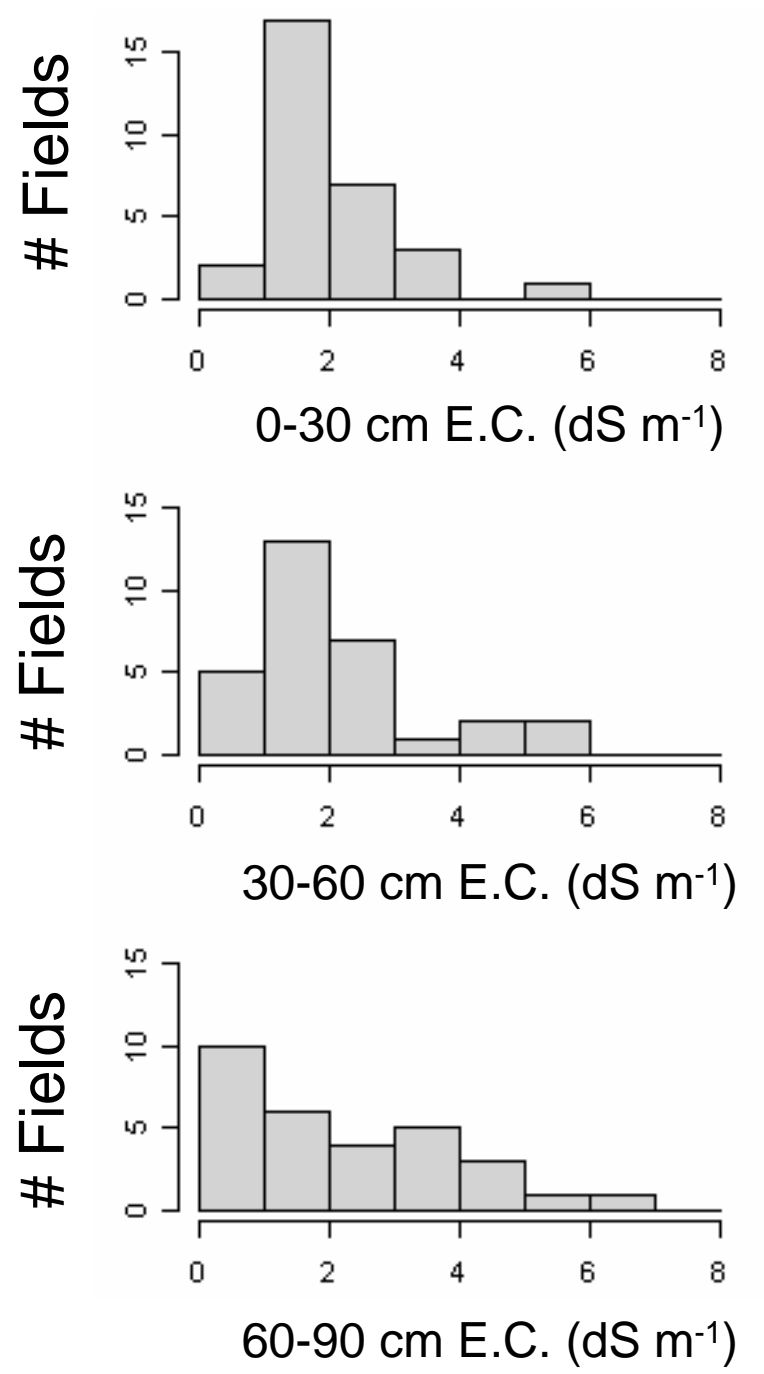

Target Group
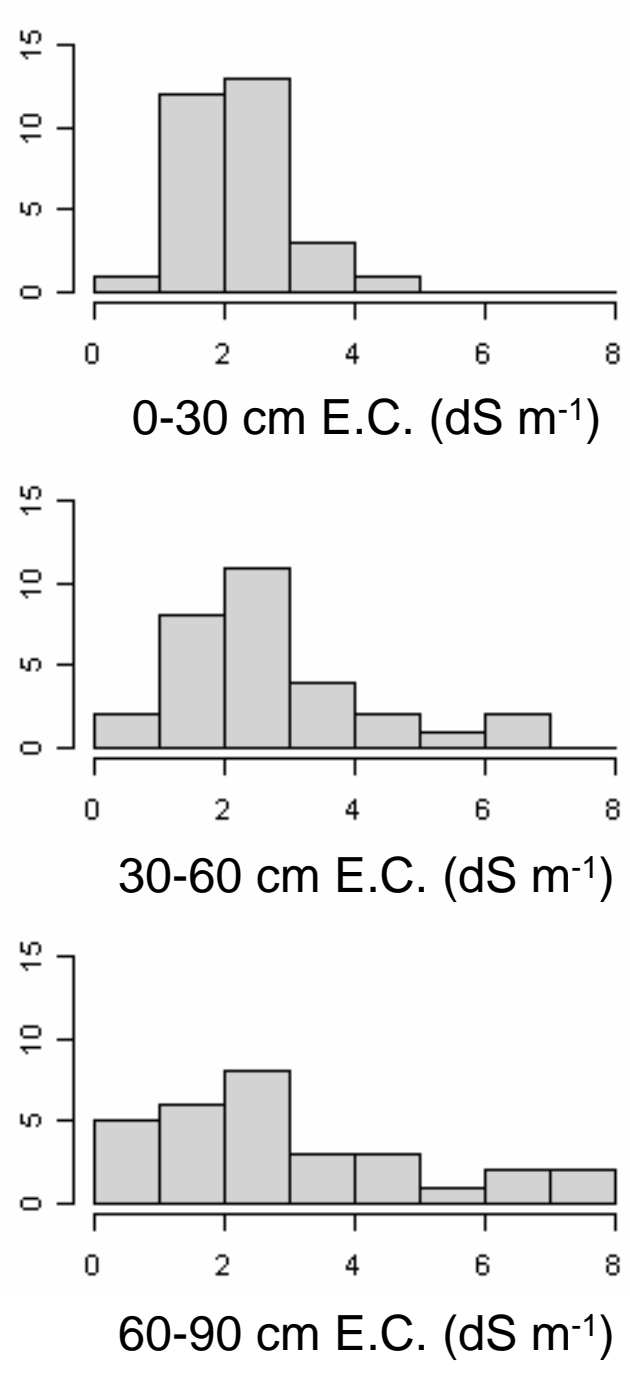